\title{
Endobronchial ultrasound is feasible and safe to diagnose pulmonary embolism in non-transportable SARS-CoV-2 ARDS patients requiring extracorporeal lung support
}

\author{
Maxens Decavele ${ }^{1,2}$ (D), Valery Trosini-Désert ${ }^{2}$, Samia Boussouar ${ }^{3}$, Baptiste Duceau ${ }^{4}$, Martin Dres ${ }^{1,2}$ and \\ Alexandre Demoule ${ }^{1,2^{*}}$
}

Dear editor,

The SARS-CoV-2 (severe acute respiratory syndrome coronavirus 2)-related acute respiratory distress syndrome (ARDS) is associated with an elevated coagulation activation pattern [1] and a high incidence of pulmonary embolism [2]. The diagnosis of pulmonary embolism (PE) may be challenging in these patients because computed tomography pulmonary angiogram (CTPA) requires an intrahospital transport with potential adverse effects and also may increase the risk of acute kidney failure (contrast-induced nephropathy). This is even more the case in up to $10 \%$ of SARS-Cov-2 ARDS patients who require venovenous extracorporeal membrane oxygenation (vv-ECMO) as an extracorporeal lung support [1]. In addition to the inherent risks of hospital transport, which are particularly high in these patients [3], extracorporeal circulation is likely to alter the quality of the contrast agent distribution and may reduce the diagnostic performance of the CTPA [4]. Finally, systematic curative antithrombotic therapy is not a safe option as it exposes to a serious risk of bleeding, especially when prolonged vv-ECMO is expected [5]. For all the abovementioned reasons, alternative techniques allowing

\footnotetext{
*Correspondence: alexandre.demoule@aphp.fr

${ }^{1}$ AP-HP, Groupe Hospitalier Universitaire APHP-Sorbonne Université, site

Pitié-Salpêtrière, Service de Pneumologie, Médecine Intensive et Réanimation (Département R3S), F-75013 Paris, France

${ }^{2}$ Sorbonne Université, INSERM, UMRS1158 Neurophysiologie Respiratoire Expérimentale et Clinique, F-75005 Paris, France

Full list of author information is available at the end of the article
}

the diagnosis of PE in these vv-ECMO patients would be of the highest interest.

Here, we describe the feasibility, safety, and diagnostic accuracy of endobronchial ultrasound (EBUS) to detect PE in patients with severe SARS-CoV-2 ARDS requiring vv-ECMO. Between April 15 and May 1, 2020, eleven patients were included. The procedure was performed using a 6.7-mm-outer-diameter, real-time, bronchoscope (EB-530US; FUJIFILM Medical Corporation, Tokyo, Japan) with a $7.5-\mathrm{MHz}$ linear ultrasound transducer (SU-1 H; FUJIFILM Medical Corporation, Tokyo, Japan) equipped with color-Doppler. For each patient, EBUS procedure followed the same roadmap [6]. All EBUS images and videos were reviewed by two independent experts in thoracic radiology (S.B. and D.T.) blind from the CTPA interpretation. The study was approved by the research ethics committee of Sorbonne University (CERSU N ${ }^{\circ} 2020-48$ ) and information was given to the patients or their relatives.

Patients were mostly men $(n=10), 52$ [49-55] years old, with a body mass index of $29[28-31] \mathrm{kg} / \mathrm{m}^{2}$ (Table 1). The time between intubation, vv-ECMO and EBUS was 21 [11-27] and 13 [7-18] days, respectively. At the time of EBUS procedure, three patients were not receiving antithrombotic therapy, two were receiving effective curative unfractionated heparin, and six were receiving prophylactic unfractionated heparin (dose was $18,000[14,000-20,000]$ UI/day). Pulmonary embolism was observed on EBUS in five of the eleven patients 


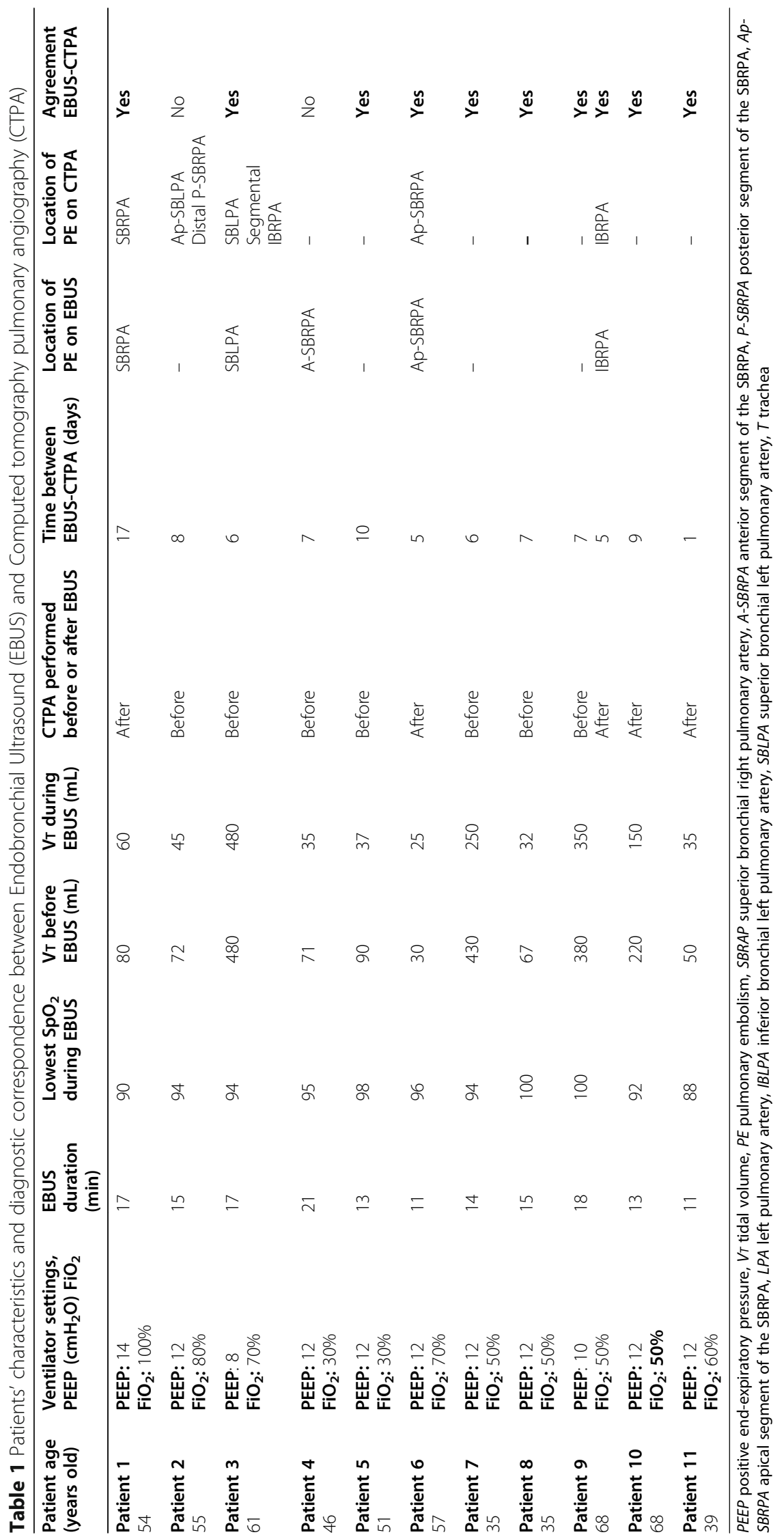




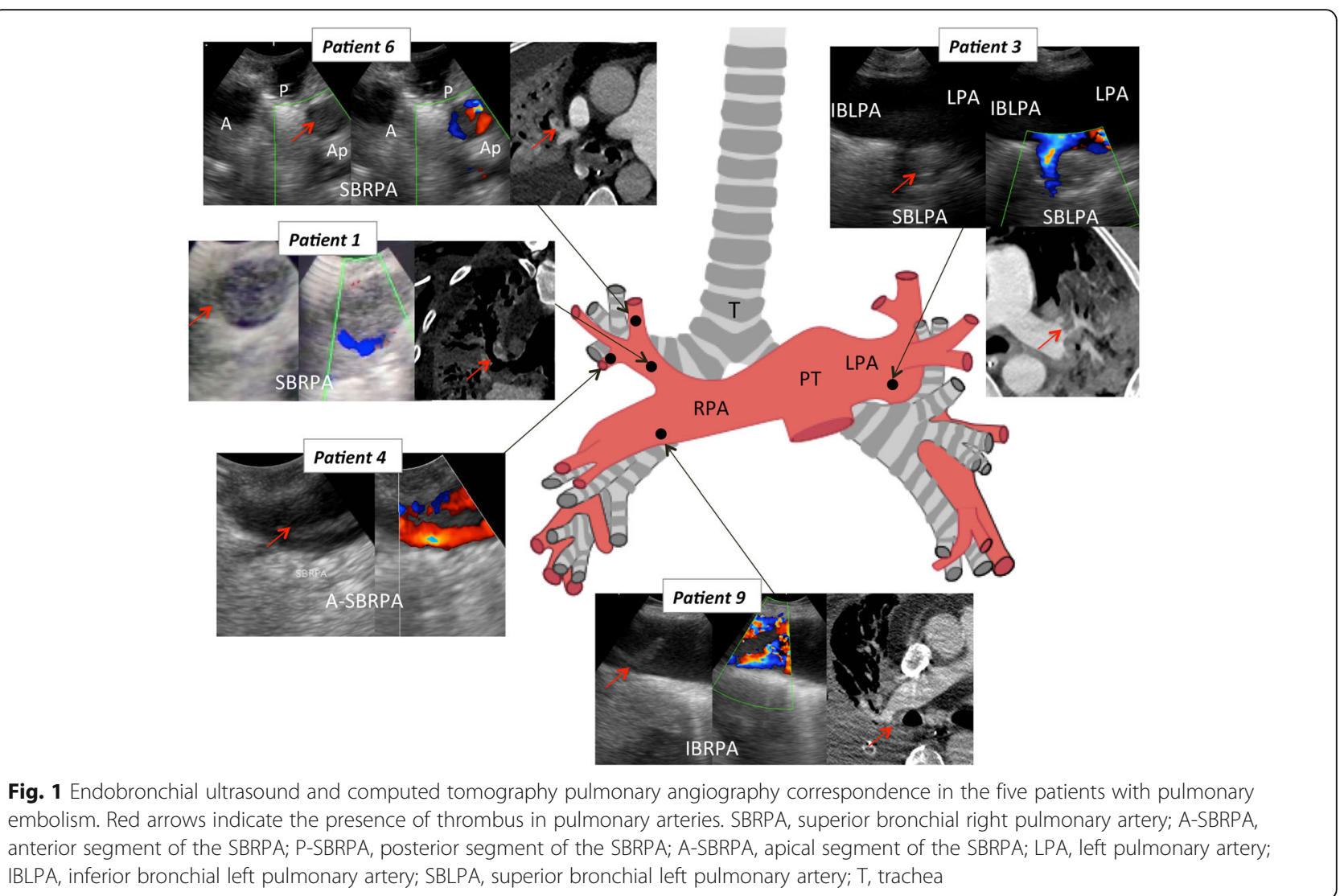

(45\%) (Fig. 1). The duration of the procedure was 15 [13-17] min and no major adverse effect of EBUS (e.g., serious bleeding, arterial oxygen saturation $<85 \%$ ) was reported. EBUS could explore part of segmental arteries in five $(45 \%)$ patients.

Diagnostic correspondence between EBUS and CTPA is depicted in Table 1. Excluding patient 4, in which PE may have developed during the 7 days that separated EBUS and CTPA, overall agreement was obtained in 9/ $10(90 \%)$ patients. The patient (patient 2) without PE on the EBUS had left segmental pulmonary embolism on CTPA, which was not accessible to the EBUS.

This case series of EBUS to diagnose PE in severe SARS-CoV-2 ARDS patients requiring vv-ECMO suggests that the EBUS procedure is safe and reliable to detect lobar and even segmental PE at bedside. Given the high risk of pulmonary embolism in patients with severe ARDS due to COVID-19, this minimally invasive diagnostic approach seems to be a useful and appropriate diagnostic tool to avoid the multiple adverse effects of CTPA in these severe and often unstable patients. The diagnostic performance of this innovative and promising technique needs now to be confronted to CTPA in larger prospective study and other clinical situations, especially for the analysis of segmental arteries.

\section{Abbreviations}

ARDS: Acute respiratory distress syndrome; Ap-SBRPA: Apical segment of the SBRPA; A-SBRPA: Anterior segment of the SBRPA; CT: Computed tomography; EBUS: Endobronchial ultrasound; IBLPA: Inferior bronchial left pulmonary artery; LPA: Left pulmonary artery; PE: Pulmonary embolism; PEEP: Positive end-expiratory pressure; P-SBRPA: Posterior segment of the SBRPA; SARSCoV-2: Severe acute respiratory syndrome coronavirus 2; SBLPA: Superior bronchial left pulmonary artery; SBRPA: Superior bronchial right pulmonary artery; T: Trachea; vv-ECMO: Venovenous extracorporeal membrane oxygenation

\section{Acknowledgements}

The authors thank Mrs. Pia Chevalier for her help in the production of Fig. 1.

\section{Authors' contributions}

Conception and design: MD, VTD, SB, AD, MD. Data acquisition: MD, VTD, JM $M D$. Analysis and interpretation: MD, VTD, SB, MD, AD. Drafting the manuscript: MD, VTD, AD, MD. Final approval: all the authors.

\section{Funding}

No funding.

\section{Availability of data and materials}

Our data are available to ensure transparency.

\section{Ethics approval and consent to participate}

The study was approved by the research ethics committee of Sorbonne University (CER-SU N²020-48) and information was given to the patients or their relatives.

Consent for publication Not applicable 


\section{Competing interests}

Dr. SIMILOWSKI reports personal fees from ADEP Assistance, AstraZeneca France, Boerhinger Ingelheim France, Chiesi France, GSK France, Lungpacer Inc., Novartis France, and TEVA France, outside the submitted work. In addition, Dr. Similowski has a patent titled "brain-ventilator interface" licensed to Air Liquide Medical Systems and MyBrainTechnology, a patent for a "protection device for intubation" pending, and a patent for a "non-contact thoracic movement imaging system" pending.

Alexandre Demoule reports personal fees from Medtronic, grants, personal fees and non-financial support from Philips, personal fees from Baxter, personal fees from Hamilton, personal fees and non-financial support from Fisher \& Paykel, grants from French Ministry of Health, personal fees from Getinge, grants and personal fees from Respinor, and grants and nonfinancial support from Lungpacer, outside the submitted work. Martin Dres received personal fees and travel expenses from Lungpacer outside the submitted work.

The other authors had no conflict of interest to declare.

\section{Author details}

'AP-HP, Groupe Hospitalier Universitaire APHP-Sorbonne Université, site Pitié-Salpêtrière, Service de Pneumologie, Médecine Intensive et Réanimation (Département R3S), F-75013 Paris, France. ${ }^{2}$ Sorbonne Université, INSERM, UMRS1158 Neurophysiologie Respiratoire Expérimentale et Clinique, F-75005 Paris, France. ${ }^{3} \mathrm{AP}-\mathrm{HP}$, Unité d'imagerie cardio-thoracique, hôpitaux universitaires Pitié-Salpêtrière Charles Foix, AP-HP, 75013 Paris, France. ${ }^{4}$ Département d'anesthésie réanimation, AP-HP, Sorbonne Université, Hôpital Pitié-Salpêtrière, Paris, France.

Received: 31 August 2020 Accepted: 14 September 2020

Published online: 21 September 2020

\section{References}

1. Helms J, Tacquard C, Severac F, Leonard-Lorant I, Ohana M, Delabranche X, Merdji H, Clere-Jehl R, Schenck M, Fagot Gandet F, Fafi-Kremer S, Castelain V, Schneider F, Grunebaum L, Anglés-Cano E, Sattler L, Mertes PM, Meziani F, CRICS TRIGGERSEP Group (Clinical Research in Intensive Care and Sepsis Trial Group for Global Evaluation and Research in Sepsis). High risk of thrombosis in patients with severe SARS-CoV-2 infection: a multicenter prospective cohort study. Intensive Care Med. 2020;46:1089-98.

2. Grillet F, Behr J, Calame P, Aubry S, Delabrousse E. Acute pulmonary embolism associated with COVID-19 pneumonia detected by pulmonary $C T$ angiography. Radiology. 2020;296:E186-8.

3. Vieira J, Frakes M, Cohen J, Wilcox S. Extracorporeal membrane oxygenation in transport part 2: complications and troubleshooting. Air Med J. 2020;39: 124-32.

4. Lambert L, Grus T, Balik M, Fichtl J, Kavan J, Belohlavek J. Hemodynamic changes in patients with extracorporeal membrane oxygenation (ECMO) demonstrated by contrast-enhanced CT examinations - implications for image acquisition technique. Perfusion. 2017;32:220-5.

5. Mazzeffi M, Greenwood J, Tanaka K, Menaker J, Rector R, Herr D, Kon Z, Lee J, Griffith B, Rajagopal K, Pham S. Bleeding, transfusion, and mortality on extracorporeal life support: ECLS working group on thrombosis and hemostasis. Ann Thorac Surg. 2016;101:682-9.

6. Li P, Wu C, Zheng W, Zhao L. Pathway and application value of exploration of the pulmonary artery by endobronchial ultrasound. J Thorac Dis. 2017;9: 5345-51.

\section{Publisher's Note}

Springer Nature remains neutral with regard to jurisdictional claims in published maps and institutional affiliations.

Ready to submit your research? Choose BMC and benefit from:

- fast, convenient online submission

- thorough peer review by experienced researchers in your field

- rapid publication on acceptance

- support for research data, including large and complex data types

- gold Open Access which fosters wider collaboration and increased citations

- maximum visibility for your research: over $100 \mathrm{M}$ website views per year

At BMC, research is always in progress.

Learn more biomedcentral.com/submissions 